\title{
EARLY COMPLICATIONS OF KEY GRIP HAND SURGERY FOR TETRAPLEGIA
}

\author{
By Arnold Graham Smith, M.B., F.R.C.S. \\ Georgia Warm Springs Hospital, Warm Springs, Georgia 31830, U.S.A.
}

\begin{abstract}
Many C6 tetraplegic patients achieve useful hand function with the help of flexor hinge orthoses. However, these devices are of little help in dressing and many of the young people who have to wear them ask whether something could be done to make their hand look more 'normal'. The lateral pinch or Key Grip operation can be performed on most people able to operate such an orthosis and the grip produced is stronger and often more useful than the three-pulp pinch.

An account of 29 cases is given and complications encountered within 3 months of surgery are outlined. The modifications suggested to overcome these complications are detailed.
\end{abstract}

Key words: Spinal cord injury; Tetraplegia; Key Grip; Hand surgery.

\section{Introduction}

THE Key Grip or lateral pinch operation for reconstruction of the tetraplegic hand was first described by Moberg in 1974 and details of over 40 cases were reported the following year. The principle of the operation depends on wrist movement. Gravity passively flexes the wrist and allows the first web space of the hand to open. Active extension of the wrist adducts the thumb, which has been stiffened by pulling tight the flexor pollicis longus, already tenodesed to the radius. The thumb adducts to the side of the passively flexed index finger, producing a lateral pinch. The procedure has a number of advantages. It is simple to do and it is a one-stage operation. It is reversible so that if the patient does not like what has been done to his hand the tenodesis can be released bringing the hand back to its original state. It is cosmetic as there is no need to stiffen the fingers and make them claw-shaped to meet the thumb in a pulp-pinch. It provides a strong pinch of several pounds rendering the patient able to discontinue the use of handsplints.

\section{Selection of Patients}

A lengthy evaluation is carried out and this is repeated on a number of occasions to make sure that the first impressions of the surgeon are accurate. Sensory function is recorded using a paper clip to measure two point discrimination. Sensation is not essential as the hand can be controlled by visual function if it has no sensitivity of its own. However, it is not possible for the eyes to watch both hands and consequently it is difficult to use both hands simultaneously if there is no sensation. Motor function requires wrist extension to be of MRC Grade IV strength to provide an adequate pinch. Classification of the motor and sensory function of each hand can be made using the new international scheme recommended in Edinburgh in 1978. Contractures, especially those at the shoulder and elbow, should be treated first as there is limited value in recon- 
structing a hand that cannot reach out to grasp. Contractures of the metacarpophalangeal joints of the fingers may need to be stretched before surgery. Spasticity, especially in the wrist flexors, is a contra-indication to Key Grip reconstruction.

Timing is important. It is unwise to begin reconstruction before nine to twelve months after injury. It is best for the patient to have left rehabilitation and gone home before considering hand surgery so that he can find out how he needs to use his hands.

\section{Technique}

The procedure has three parts in its simplest form. First, the annular ligament at the base of the thumb is released, the same procedure that is done for trigger thumb. This allows the long flexor tendon of the thumb to bowstring into the palm thus adding to the strength of the thumb in the adducted position. Second, the interphalangeal joint of the thumb is stiffened by inserting a Steinmann pin through the thumb tip across the distal and proximal phalanges. The advantage of this procedure is that it saves the 6 weeks which a bony arthrodesis would take to mature and enables the hand to begin training quicker. Third, the long flexor of the thumb is tenodesed to the distal radius. Two small windows are made in the bone and the proximally divided tendon is threaded through and stitched to itself in a loop. The advantage of this tenodesis over the use of a staple is that the tension can be carefully adjusted during the operation. If the tendon had been stapled to the bone it might be frayed and would be difficult to replace. At the end of the procedure a backslab of plaster of Paris is applied to the forearm and hand to keep the wrist motion still for 3 weeks while the tenodesis heals. The cast is well padded inside to prevent pressure sores and the patient needs to be taught a one-handed means of raise or ischial pressure relief.

After removal of the cast and sutures the patient learns to roll the fingers first and then begins graduated training, moving pegs around a pegboard and doing more difficult exercises until finally functional training teaches him to use feeding implements and a pen.

\section{Material}

This report is of 29 Key Grip operations, 2I of which were done at Rancho Los Amigos Hospital in Downey, California, and eight at Georgia Warm Springs Hospital. Twenty-six were male and one female; two of the males returned to have the second hand reconstructed. In addition to the basic operation which has been described, a number of additional procedures may need to be done simultaneously to improve the function of the Key Grip. Twenty-two hands in this series had additional procedures.

(I) For the thumb which has an excessive range of flexion at the metacarpophangeal joint it is necessary to tenodese the extensor pollicis longus to the first metacarpal shaft. The dorsal surface of the shaft is exposed and several small drill holes are made on either side and the tendon is bound down by sutures going through the bone and around the tendon. This is necessary because the thumb will jack-knife and the distal pulp will slide off the proximal index finger if there is too great a range of flexion at the MP joint.

(2) Some patients who have damaged the volar plate of the thumb metacarpophalangeal joint have hyperextension of this joint. This may have been 
caused by falls from the wheelchair in which the thumb is bent back or by misuse of the hand in propelling the wheelchair. For this joint laxity, it is necessary to do an arthrodesis using an extra long Steinmann pin crossing the IP and MP joints thus stiffening the entire thumb.

(3) For most patients, wrist extension is provided adequately by the wrist extensors. For four of the patients in this series wrist extension was an inadequately strong motion at the time of evaluation. Consequently a transfer of the brachioradialis tendon as described by Freehafer and Mast (1967) was required to increase the strength of wrist extension. One of the patients in this series relied entirely on the tendon transfer for his wrist extension.

\section{Results}

There were six pin complications in the first 13 cases. Initially a smooth Steinmann pin was used and three pins penetrated the metacarpophalangeal joint and three extruded from the thumb tip. When the pins were relocated a good result from the operation was achieved. After these complications a threaded pin was used with a slot cut in the top of it to take a screwdriver. These were pre-cut in four lengths from $\mathrm{I} \frac{3}{4}$ inches to $2 \frac{1}{8}$ inches and this range of sizes has been adequate for all the thumbs operated on. The pin is inserted using a regular Steinmann pin introducer through the distal tuft immediately underneath the nail of the thumb and it is tightened with an electrical screwdriver. An operative radiograph is taken to make sure that the pin is in good position. None of these pins have moved since the technique was changed.

One Key Grip was too loose so that when the wrist came into full extension there was an inadequate grip. It is necessary to get a fine balance here. The web space should be wide enough to grip a bottle or can and yet the pinch must be tight enough to mean that a regular writing implement, not a special one with a non-slip surface, can be held. At the time of making the tenodesis the thumb should be resting firmly against the side of the index finger with the wrist in neutral position. Extension of the wrist about 30 degrees should then produce a tight grip. In the case where the tension was too loose the flexor pollicis longus tendon was reefed distally. The result of this was an entirely satisfactory Key Grip.

Fourteen dorsal tenodeses of the extensor pollicis longus were done and two stretched out. The stretching was due to enthusiastic use of the grip by the patients before the tenodesis had matured. It is suggested that a loop tenodesis of extensor pollicis longus to the metacarpal shaft should be done similar to that of the flexor pollicis longus to the radius instead of the 'binding down' technique that was described initially. It is important to tell the patient not to use it too strenuously in the first 6 to 8 weeks.

Four brachioradialis tendon transfers were done to assist wrist extension and two of them failed. One of them was a man in whom the brachioradialis alone was responsible for wrist extension and the other was a man who had very weak wrist extensors and a fairly weak brachioradialis initially. The failure of this tendon transfer to produce adequate power is because the brachioradialis muscle is still acting across the elbow joint as an elbow flexor. It is now recommended that stabilisation of the elbow joint by construction of an extensor by deltoid to triceps transfer should be done first. The transferred brachioradialis thus effectively acts only across the wrist joint, as the elbow is held still by its new extensor. 


\section{SUMMARY}

Twenty-nine Key Grip procedures are reported. Six required revision operations, all with successful outcome. Five were for pin complications and one was a Key Grip which had to be tightened. Two extensor pollicis longus dorsal tenodeses stretched out, weakening the strength of the grip. There were two failures which occurred because of brachioradialis tendon transfer problems. Three modifications of technique are recommended which should lead to a reduction in the frequency of complications.

\section{RÉSUMÉ}

Un grand nombre de tétraplégiques de niveau C-6 accomplissent une fonction utile de la main avec l'aide d'une orthose charnière permettant la flexion. Toutefois, ces devises sont d'aide insignifiante dans l'activité de l'habillement, et beaucoup de jeunes personnes qui doivent les porter posent la question, si l'on pourrait faire quelque chose pour donner une apparence normale à leur main. La pince latérale ou l'opération appellée prise de clef peut s'excéuter sur la majorité de personnes capables de manœuvrer telle orthose et la prise produite est plus forte et souvent plus utile que la pince de trois pulpes.

Un exposé de vingt-neuf cas est soumis et les complications renontrées trois mois après intervention chirurgicale sont tracées.

Les modifications suggérées pour surmonter ces complications sont détaillées.

\section{ZUSAMMENFASSUNG}

Viele C-6 Tetraplegie-Patienten erhalten mit Hilfe der 'Flexor-hinge' Orthese wieder gebrauchsfähige Handfunktionen. Trotzdem sind diese Geräte beim Ankleiden nicht von großer Hilfe, und viele der jungen Leute, die von der Orthese Gebrauch machen, fragen sich, ob man nicht etwas tun könnte, um ihre Hand 'normaler' aussehen zu lassen. Die 'Laterale-Griff-' oder 'Schlüsselgriff-Operation' (Daumen gegen gebeugten Zeigefinger) kann bei den meisten Leuten vorgenommen werden, die so eine Korrektur benützen können. Dieser Griff ist kräftiger und oft praktischer als der Griff mit drei Fingerspitzen.

Neunundzwanzig Beispielfälle und entstehende Komplikationen im Zeitraum von drei Monaten nach der Operation werden besporchen. Die zur Vermeidung dieser Komplikationen geeignet gehaltenen Abänderungen werden ebenfalls besprochen.

\section{REFERENCES}

FReEhAFER, A. A. \& MAST, W. A. (I967). Transfer of the Brachioradialis to improve wrist extension in high spinal cord injury. F. Bone and foint Surg., 49A, 648-652.

McDowell, C. L., Moberg, E. \& Graham Smith, A. (1979). Proceedings: International Conference on Surgical Rehabilitation of the Upper Limb in Tetraplegia. F. of Hand Surgery, 4, 4, 387-390.

MoBERG, E. (I974). Upper limb surgery as a help to $\mathrm{C}_{5}-6$ tetraplegia. F. Bone and foint Surg., 56B, 206.

MoBERG, E. (1975). Surgical treatment for absent single hand grip and elbow extension in quadriplegia. F. Bone and foint Surg., 57A, 196-206.

MoBERG, E. (1976). Reconstructive hand surgery in tetraplegia, stroke and cerebral palsy: some basic concepts in physiology and neurology. F. of Hand Surg., I29-I 34 .

MOBERG, E. (1978). The upper limb in tetraplegia, a new approach to surgical rehabilitation. Stuttgart, Thieme. 